\title{
Ornithine Aminotransferase Messenger RNA Expression and Enzymatic Activity in Fetal Porcine Intestine
}

\author{
CHRISTOPHER M. DEKANEY, GUOYAO WU, AND LAURIE A. JAEGER \\ Departments of Veterinary Anatomy and Public Health [C.M.D., G.W., L.A.J.] and Animal Science \\ [G.W., L.A.J.], and Center for Animal Biotechnology and Genomics [L.A.J.], Institute of Biosciences \\ and Technology, Texas A\&M University, College Station, Texas 77843-4458 U.S.A.
}

\begin{abstract}
ABST
In most neonatal animals, the small intestinal epithelium is
responsible for endogenous arginine production. The ability of
neonatal enterocytes to synthesize arginine immediately after
birth suggests that the enzymes involved are present prenatally.
Pyrroline-5-carboxylate is the common intermediate in the intes-
tinal pathways for the synthesis of citrulline and arginine from
both glutamine and proline and is interconverted into ornithine
by ornithine aminotransferase (OAT). In this study, OAT enzy-
matic activity and mRNA expression in the intestine of fetal pigs
from 30 to $110 \mathrm{~d}$ of gestation were determined. Enzymatic
activity (nanomoles per minute per milligram of protein) peaked
at 45 of gestation and increased again between 60 and 110 of
gestation. At 30 and $35 \mathrm{~d}$ of gestation, OAT mRNA expression
was detected throughout the mucosal epithelium of the small
intestine. Throughout the remainder of gestation, OAT expres-
\end{abstract}
Milk of many species, including human, cow, and pig, is relatively deficient in arginine (1). Additionally, arginine requirements by neonates are particularly high, partly because of arginine abundance in the body and multiple metabolic pathways for arginine utilization (2). Arginine is used for synthesis of proteins, polyamines, creatinine, and nitric oxide (3). Thus, endogenous synthesis of arginine must play an important role in arginine provision to the breast-fed neonate (3), and development of the intestinal arginine synthetic pathway before parturition is of crucial importance for neonatal survival and growth.

Both enzymologic and metabolic studies have established that enterocytes of the small intestine synthesize citrulline and arginine from glutamine and proline (Fig. 1) and are the major site for endogenous synthesis of arginine in neonates (2). OAT (EC 2.6.1.13) interconverts $\mathrm{P}-5-\mathrm{C}$ and ornithine; $\mathrm{P}-5-\mathrm{C}$ is the

Received May 11, 2000; accepted January 23, 2001.

Correspondence and reprint requests: L.A. Jaeger, D.V.M., Ph.D., Room 107 VMA, College of Veterinary Medicine, College Station, TX 77843-4458, U.S.A.; e-mail: ljaeger@cvm.tamu.edu

Supported in part by NIH Environmental and Rural Health Grant (P30-ES09106) and by funds from the Texas A\&M University College of Veterinary Medicine. sion was notably higher in the villus epithelium than in the crypt epithelium. The presence of OAT in the small intestinal epithelium throughout gestation suggests that the porcine small intestine is capable of interconverting ornithine and pyrroline-5carboxylate during fetal development. This capability may be important for synthesis of arginine, proline, ornithine, and polyamines for development and metabolic activity of the intestine during gestation or for somatic growth of the fetus. (Pediatr Res 50: 104-109, 2001)
ISH, in situ hybridization
OAT, ornithine aminotransferase
P-5-C, pyrroline-5-carboxylate

\section{Abbreviations}

common intermediate in the intestinal pathways for the synthesis of citrulline and arginine from both glutamine and proline (Fig. 1). Thus, OAT plays an essential role in intestinal synthesis of citrulline and arginine. Consistent with this notion, hypoornithinemia, hypocitrullinemia, and hypoargininemia occur in OAT-deficient infants (4) and neonatal pigs (5), as well as in OAT-gene knockout newborn mice (4). The severity of OAT deficiency varies among species, and associated pathologic conditions are not realized until after birth. In OAT knockout mice OAT deficiency is lethal in neonates (4). In humans, OAT deficiency normally remains undetected until retinal degeneration associated with gyrate atrophy is diagnosed (4).

Little is known about intestinal OAT in the developing fetal small intestine. In this study, we focused on the ontogeny of expression of OAT, an enzyme that plays a central role in the synthesis of citrulline and arginine from both glutamine and proline $(2,6)$, in the fetal porcine small intestine. We used both morphologic and biochemical techniques to identify distribution of OAT mRNA expression along the intestinal crypt-villus axis and intestinal OAT enzyme activity. This information will 


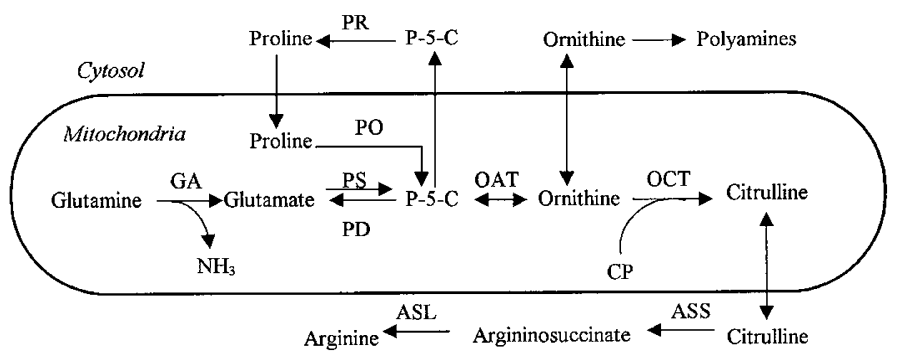

Figure 1. Biosynthetic pathway for production of arginine from glutamine in porcine enterocytes. $C P$, carbamoyl phosphate; GA, glutaminase; PS, P-5-C synthase; $P D$, P-5-C dehydrogenase; $O C T$, ornithine carbamoyltransferase; $A S S$, argininosuccinate synthase; $A S L$, argininosuccinate lyase; $P R$, P-5-C reductase; $P O$, proline oxidase.

aid in understanding the metabolic zonation in fetal intestinal arginine synthesis. Results of this study demonstrated that 1) OAT enzymatic activity, expressed per milligram of intestinal protein, peaked on $\mathrm{d} 45$ of gestation and increased again between d 60 and 110 of gestation, 2) OAT mRNA, as detected by ISH, was expressed in enterocytes of fetal pig intestine from d 30 to 110 of gestation, and 3) OAT mRNA expression was localized primarily to villus cells during fetal development.

\section{METHODS}

Animals. Fetuses were collected from crossbred (Duroc $\times$ Hampshire $\times$ Yorkshire) gilts at defined stages of gestation using procedures approved by the Texas A\&M Laboratory Animal Care Committee and as reported previously (6). Briefly, gilts were monitored daily, hand-mated to boars at 12 and $24 \mathrm{~h}$ after the onset of their second estrus, and hysterectomized at defined intervals between $\mathrm{d} 30$ and 110 of gestation (term is $114 \pm 2 \mathrm{~d}$ ). Fetuses were euthanized by decapitation, and small intestines were collected on d 30, 35, 40, 45, 60, 90, and 110 of gestation. Whole intestines were used for measuring OAT activity in d 30-45 fetuses, whereas whole small intestines were used for d 60-110 fetuses. For ISH, small intestines were divided into duodenal and proximal and distal jejunal segments. The small intestine of $\mathrm{d} 30$ fetuses was too small and fragile to be divided into regions. In fetuses $>30 \mathrm{~d}$ of age, a segment of descending duodenum was isolated midway between the pyloric sphincter and the caudal duodenal flexure. The jejunum was defined as that portion of the small intestine between the duodenojejunal flexure and the ileal-cecal fold. The jejunum was divided approximately in half, and segments were isolated from the middle third of both the proximal and distal jejunal segments and designated as proximal and distal jejunum, respectively. Tissue samples were fixed in 4\% paraformaldehyde overnight, and then stored in 70\% ethanol before processing and paraffin embedding.

Measurement of $\boldsymbol{O A T}$ activity. OAT enzyme activity was determined in homogenates of fetal small intestines from d 30 , $35,45,60,90$, and 110 of gestation using previously reported methods (5). Whole intestines pooled from 8-10 fetuses of each litter ( $n=8$ litters) on d 30, 35, and 45 and small intestines from four individual fetuses per litter $(n=8$ litters) on d 60, 90, and 110 of gestation were used for assay of OAT activity. Briefly, whole intestine (d 30, 35, and 45) or small intestine ( $\mathrm{d} 60,90$, and 110) were homogenized at $4^{\circ} \mathrm{C}$ in homogenization buffer (0.33 M sucrose, $5 \mathrm{mM}$ HEPES, $1 \mathrm{mM}$ EGTA, 1 mM DTT, $0.5 \%$ Triton X-100, pH 7.4). Homogenates were subjected to three cycles of freezing in liquid nitrogen and thawing at $37^{\circ} \mathrm{C}$ and centrifuged at $600 \times g$ for $10 \mathrm{~min}$. Supernatants were added to an assay mixture consisting of 75 $\mathrm{mM}$ potassium phosphate buffer $(\mathrm{pH} 7.5), 20 \mathrm{mM}$ ornithine, $0.45 \mathrm{mM}$ pyridoxal phosphate, $5 \mathrm{mM}$-aminobenzaldehyde, and 0 or $3.75 \mathrm{mM} \alpha$-ketoglutarate, and incubated for $15 \mathrm{~min}$ at $37^{\circ} \mathrm{C}$. The activity of OAT was quantified by measuring the absorbance of the colorimetric reaction product of P-5-C with $o$-aminobenzaldehyde at $440 \mathrm{~nm}$. Enzymatic activity was expressed based on total protein, which was determined using a modified Lowry procedure (6).

Northern blot analysis. Total RNA from small intestine of fetal pigs on d 40 of gestation was isolated using TriPure Isolation Reagent (Roche Molecular Biochemicals, Indianapolis, IN, U.S.A.) according to the manufacturer's directions. Total small intestinal RNA $(10 \mu \mathrm{g})$ was electrophoresed through a $1 \%$ agarose-formaldehyde gel and transferred overnight to a positively charged nylon membrane by capillary blotting with $10 \times \mathrm{SSC}(1 \times \mathrm{SSC}$ is $150 \mathrm{mM} \mathrm{NaCl}$ and $15 \mathrm{mM}$ sodium citrate). The blot was prehybridized in hybridization buffer (50\% formamide, $50 \mathrm{mM} \mathrm{Na}_{2} \mathrm{PO}_{4}, 5 \times \mathrm{SSC}, 0.1 \% \mathrm{SDS}$, $1 \mathrm{mM}$ EDTA, $0.5 \times$ Denhardt's solution, and $200 \mu \mathrm{g} / \mathrm{mL}$ herring sperm DNA) for $1 \mathrm{~h}$ at $55^{\circ} \mathrm{C}$. Hybridization was performed for $16 \mathrm{~h}$ at $55^{\circ} \mathrm{C}$ using an antisense ${ }^{32} \mathrm{P}$-labeled cRNA probe $\left(1.5 \times 10^{6} \mathrm{cpm} / \mathrm{mL}\right)$ generated from an $1137-\mathrm{bp}$ $B a m \mathrm{HI} / E c o$ RI fragment from the OAT cDNA clone rOAT6 which had been subcloned into pBluescript (Promega Corporation, Madison, WI, U.S.A.). The blot was washed in $1 \times \mathrm{SSC}$ and $0.1 \% \mathrm{SDS}$ at room temperature for $20 \mathrm{~min}$ and three times in $0.2 \times \mathrm{SSC}$ and $0.1 \% \mathrm{SDS}$ for $20 \mathrm{~min}$ at $68^{\circ} \mathrm{C}$.

ISH. After determining that OAT activity was present in $\mathrm{d}$ 30-110 fetal intestines, ISH was conducted to determine the site(s) of OAT synthesis and to more definitively assess OAT expression in fetal small intestine, during the period of villus morphogenesis (i.e. $\mathrm{d} 35-45)$ and the remainder of gestation (7). Sense and antisense $\left[\alpha-{ }^{35}\right.$ S]UTP-labeled OAT cRNA probes were generated from the same rOAT subclone described above, using T3 and T7 RNA polymerase, respectively. ISH analysis was performed using previously described methods $(8,9)$ with modification of the hybridization temperature. Briefly, paraffin-embedded tissue sections of small intestine from fetal pigs on gestational d 30, 35, 40, 45, 60, 90, and 110 were cut $(4 \mu \mathrm{m})$, placed on Superfrost-Plus-coated slides (Statlab Medical Products, Lewisville, TX, U.S.A.), deparaffinized, and prehybridized at $42^{\circ} \mathrm{C}$ for $2 \mathrm{~h}$. Slides were then hybridized with sense or antisense probes at $55^{\circ} \mathrm{C}$ overnight, washed to remove nonspecific hybridization, and layered with Kodak autoradiographic emulsion NTB-2. Several ISH experiments were conducted, and each experiment included sections of the small intestine segments (duodenum, proximal or distal jejunum) from one representative fetus from two to three litters for each day of gestation studied. A total of two fetuses from each of three litters were analyzed for each gestational day studied. Preliminary experiments determined that a 3-wk exposure was sufficient to detect OAT expression at a stage (d 30) when the 
lowest OAT activity levels had been detected. Thus, all slides were subjected to a 3-wk exposure period after which they were developed in Kodak D-19 developer (Eastman Kodak, Rochester, NY, U.S.A.) and counterstained with hematoxylin. Evaluation of sections was performed using a Zeiss Axioplan II Research microscope (Carl Zeiss, Inc., Thornwood, NY, U.S.A.), under bright-field and dark-field illumination, comparing sense and antisense signal for determination of cellspecific expression. Digital images were acquired using a Zeiss Axioplan II Research microscope interfaced with a Hamamatsu color camera (Hamamatsu Corp., Bridgewater, NJ, U.S.A.) supported by a Power Macintosh G3 Computer (Apple, Cupertino, CA, U.S.A.). Images were captured and processed using Adobe Photoshop 5.0 (Adobe Systems Incorporated, San Jose, CA, U.S.A.).

\section{RESULTS}

OAT enzyme activity. OAT enzymatic activity in small intestine of fetal pigs (Table 1) was detectable at d 30 of gestation $\left(2.6 \pm 0.13 \mathrm{nmol} \cdot \mathrm{min}^{-1} \cdot \mathrm{mg}\right.$ protein ${ }^{-1}$; mean \pm SEM), at a stage at which the intestine is an immature tube of undifferentiated, stratified epithelium (7). By d 35 of gestation, when the fetal small intestinal mucosa is characterized by rudimentary villi and stratified epithelium (7), OAT activity $\left(43.6 \pm 2.8 \mathrm{nmol} \cdot \mathrm{min}^{-1} \cdot \mathrm{mg}\right.$ protein $\left.{ }^{-1}\right)$ increased 16-fold (Table 1). On $\mathrm{d} 45$ of gestation the villi are well defined and the mucosal epithelium of the fetal intestine is a monolayer of columnar epithelium containing absorptive, goblet, and enteroendocrine cell types (7). Concomitant with the development of a more differentiated epithelium at this stage of gestation, OAT enzyme activity $\left(228 \pm 13.3 \mathrm{nmol} \cdot \mathrm{min}^{-1} \cdot \mathrm{mg}\right.$ protein $^{-1}$ ) was the highest among all gestational ages studied and 87 -fold greater than the value for $\mathrm{d} 30$ of gestation (Table 1). By d 60 of gestation the major morphologic changes in the mucosa are complete (7), and at this time, OAT activity (86.6 $\pm 4.9 \mathrm{nmol} \cdot \mathrm{min}^{-1} \cdot \mathrm{mg}$ protein $\left.{ }^{-1}\right)$ had decreased significantly relative to the activity detected at $\mathrm{d} 45$. Between $\mathrm{d} 90$ and 110 of gestation, the absorptive epithelium of the fetal pig intestine resembles that described for neonatal piglets (7). OAT enzymatic activity at $\mathrm{d} 90\left(142 \pm 9.6 \mathrm{nmol} \cdot \mathrm{min}^{-1} \cdot \mathrm{mg}\right.$ protein $\left.{ }^{-1}\right)$ and $\mathrm{d} 110\left(185 \pm 9.3 \mathrm{nmol} \cdot \mathrm{min}^{-1} \cdot \mathrm{mg}\right.$ protein $\left.{ }^{-1}\right)$ increased by 64 and $114 \%$, respectively, compared with OAT enzymatic activity on $\mathrm{d} 60$ of gestation.

To determine whether the changes in calculated OAT activity resulted from specific alteration of activity of the OAT enzyme or from changes in overall protein content of the intestines, we calculated OAT activity on the basis of whole intestine (small intestine) and total intestinal (small intestinal) wet weight (Table 1). Expression of OAT activity per whole intestine $(\mathrm{d} 30-45)$ or small intestine $(\mathrm{d} 60-110)$ indicates that total intestinal OAT activity increases with gestational age (Table 1). Expression of OAT activity per wet weight of whole (d 30-45) or small (d 60-110) intestine results in a trend similar to that reported above for OAT activity expressed per protein. Overall protein content of our tissues remained relatively constant at approximately $8-10 \%$ of the wet weight of the tissue (Table 1).

Northern blot analysis. To confirm the specificity of the OAT probe used for ISH, Northern blot analysis was performed using total RNA from intestine of a d 40 fetal pig (Fig. 2). A $2.1-\mathrm{kb}$ transcript of expected size was detected $(10,11)$. Although the sequence of the porcine OAT cDNA has not been determined, the hybridization signal obtained under high stringency suggests that the porcine transcript has high homology with the rat OAT nucleotide sequence.

OAT mRNA expression. ISH analysis indicated that OAT mRNA expression in fetal small intestine was confined to the epithelium on all days of gestation and in all intestinal segments studied. In the pig, the entire intestine has retracted into the peritoneal cavity before $\mathrm{d} 30$ of gestation. The OAT mRNA expression was detected at d 30 of gestation, the earliest day studied, throughout the immature, stratified epithelium; however, a stronger signal was detected in those epithelial cells immediately adjacent to the basal lamina (Fig. 3). We have reported that at d 35 of gestation, villus development in intestine from fetal pigs occurred in a proximal-distal direction (7). This development includes compartmentalization of the intestinal epithelium into villus and intervillus regions. Expression of OAT on d 35 of gestation appeared to parallel this proximal-distal gradient, with duodenal OAT expression higher in the villus epithelium (Fig. 4A), whereas expression in proximal (Fig. 4B) and distal jejunum (Fig. 4C) remained present throughout the epithelium. By d 40 the villus epithelium had developed from stratified to simple columnar, whereas the intervillus areas remained stratified. At this time, expression of OAT was similar in duodenum and proximal (Fig. 5A) and distal jejunum, and the signal was concentrated in the infranuclear area of villus epithelium. Although the abundance of silver grains precluded specific quantitation of

Table 1. OAT activity expressed per milligram of protein, whole intestine, and gram of intestinal wet weight

\begin{tabular}{|c|c|c|c|c|}
\hline $\begin{array}{l}\text { Gestational } \\
\text { age } \\
\text { (d) }\end{array}$ & $\begin{array}{c}\text { OAT activity } \\
\left(\mathrm{nmol} \cdot \mathrm{min}^{-1} \cdot \mathrm{mg} \text { protein }\right. \\
\end{array}$ & $\begin{array}{c}\text { OAT activity } \\
(\mu \mathrm{mol} / \mathrm{min} \text { per } \\
\text { whole small intestine })\end{array}$ & $\begin{array}{c}\text { OAT activity } \\
\left(\mu \mathrm{mol} \cdot \mathrm{min}^{-1} \cdot \mathrm{g}^{-1}\right. \\
\text { of small intestine })\end{array}$ & $\begin{array}{c}\text { Protein content } \\
\text { of small intestine } \\
(\%)\end{array}$ \\
\hline 30 & $2.6 \pm 0.13 *$ & $0.002 \pm 0.0001 *$ & $0.20 \pm 0.01 *$ & $8.20 \pm 0.51 *$ \\
\hline 45 & $228 \pm 13.3^{*}$ & $6.75 \pm 0.39 *$ & $22.3 \pm 1.25^{*}$ & $9.24 \pm 0.67 *$ \\
\hline 60 & $86.6 \pm 4.6$ & $15.5 \pm 0.88$ & $8.19 \pm 0.44$ & $9.55 \pm 0.62$ \\
\hline 90 & $142 \pm 9.6$ & $96.3 \pm 6.51$ & $14.0 \pm 0.92$ & $9.81 \pm 0.52$ \\
\hline
\end{tabular}

Data are mean \pm SEM, $n=8$ litters.

* Whole intestine used for analyses. 


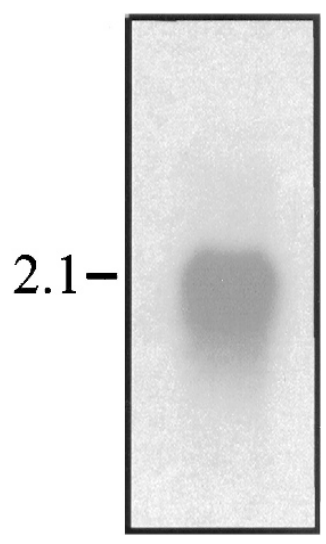

Figure 2. The 2.1-kb OAT transcript in total RNA from small intestine of fetal pigs detected by Northern blot analysis. Weak, nonspecific hybridization was detected for both $28 \mathrm{~S}$ and $18 \mathrm{~S}$ bands.

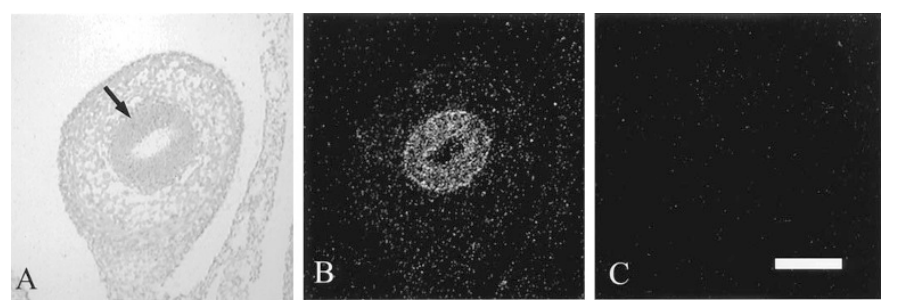

Figure 3. Expression of OAT mRNA in d 30 intestine. $A$, bright-field image. Note the stratified, immature epithelium (arrow). B, dark-field image. The expression of OAT mRNA is distributed throughout the epithelium. $C$, darkfield image of the sense control. Bar equals $100 \mu \mathrm{m}$.
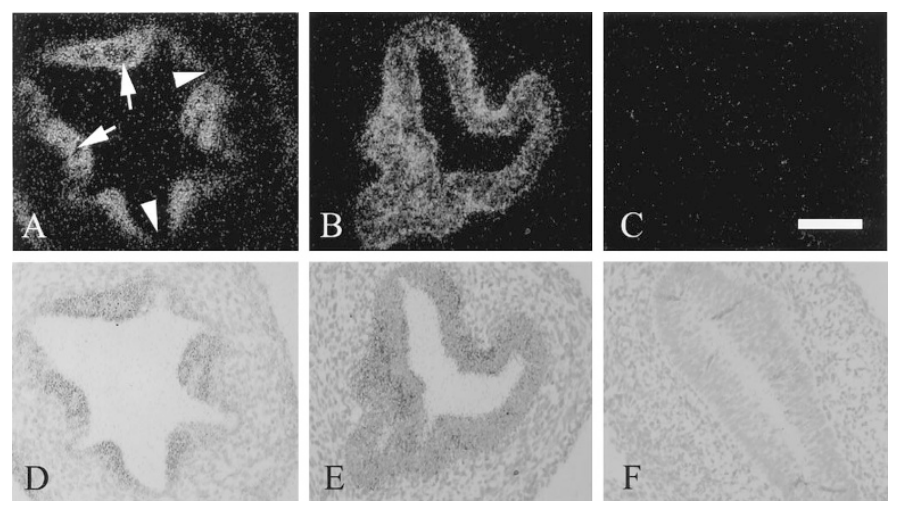

Figure 4. Darkfield $(A, B, C)$ and corresponding brightfield $(D, E, F)$ images illustrating proximal-distal gradient of OAT mRNA expression in small intestine from fetal pigs on d 35 of gestation. $A$, expression of OAT mRNA in the duodenum was most abundant in epithelium covering the nascent villi (arrow), and diminished OAT mRNA expression was detected in the intervillus areas (arrowhead). B, OAT mRNA expression was distributed throughout the epithelium of the proximal jejunum. $C$, OAT mRNA expression for distal jejunum was minimal. Bar equals $100 \mu \mathrm{m}$.

the ISH signal, expression of OAT mRNA at d 45 of gestation (Fig. $5 B$ ) appeared to be higher than for previous days of gestation in all three small intestinal segments. Between d 60 and 110, expression of OAT mRNA (Fig. 5, $C, G$, and $H$ ) was notably higher in the villus epithelium than in the crypt epithelium and was similar in all three small intestinal regions studied.
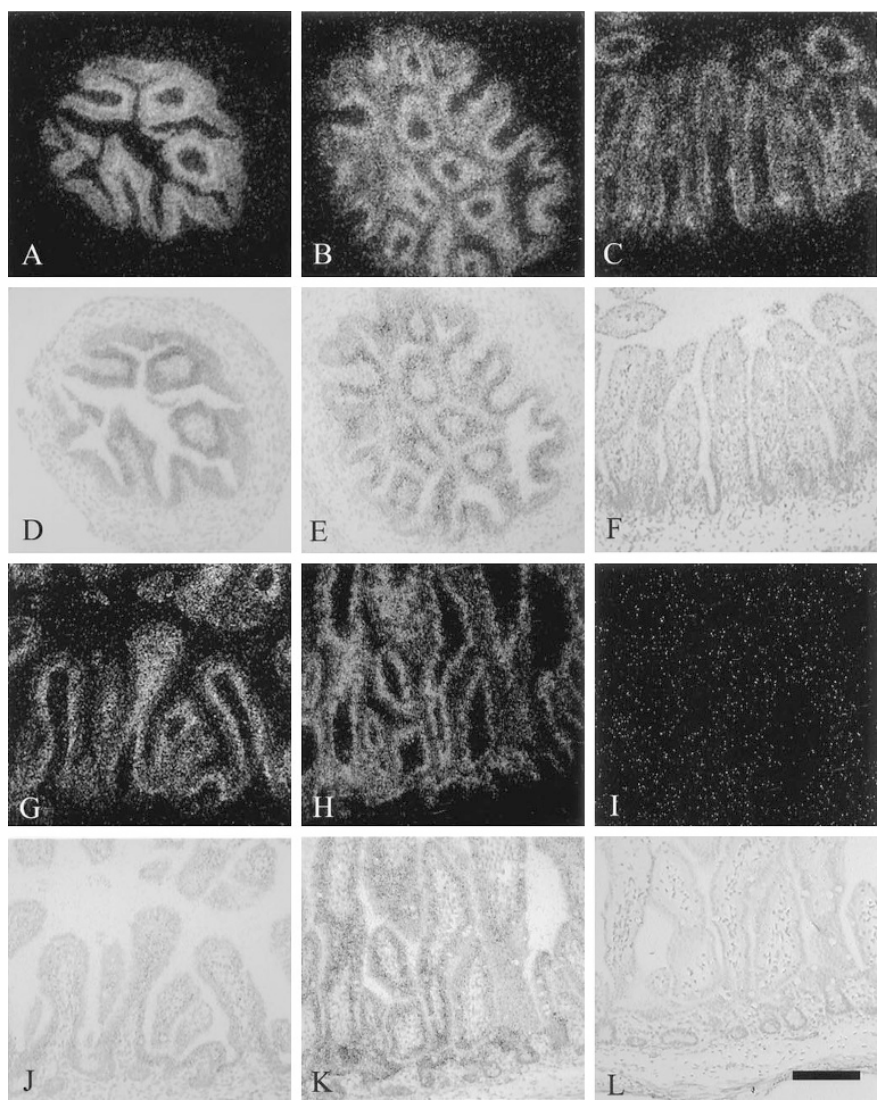

Figure 5. Expression of OAT mRNA is confined to the mucosal epithelium in the proximal jejunum of fetal pigs between d 40 and d 110 of gestation. Representative dark-field and corresponding bright-field micrographs for $\mathrm{d} 40$ $(A, D), \mathrm{d} 45(B, E), \mathrm{d} 60(C, F), \mathrm{d} 90(G, J)$, and d $110(H, K)$ demonstrate the expression of OAT mRNA in the villus epithelium. $I$ and $L$, sense control and corresponding bright-field image, respectively. Bar equals $100 \mu \mathrm{m}$.

\section{DISCUSSION}

In most species, including pigs, the adult and neonatal small intestines play key roles in endogenous arginine synthesis. In neonatal animals, the small intestine serves as the source of endogenous arginine, using glutamate (12), glutamine, or proline $(13,14)$ as substrates, to supplement arginine-deficient maternal milk (5). The enzymatic cascade that produces arginine from these substrates requires OAT (Fig. 1). Treatment of freshly isolated enterocytes from 4-d-old piglets or of 4-d-old piglets in vivo with gabaculine, an inhibitor of OAT, reduces cellular concentration and plasma levels, respectively, of ornithine, citrulline, and arginine (5). Similarly, neonatal OAT knockout mice and human infants with OAT deficiency have low plasma levels of ornithine and arginine relative to their normal counterparts (4). Loss of OAT activity in neonatal OAT knockout mice is lethal, presumably owing to disruption of the urea cycle, whereas in humans OAT deficiency is usually not detected until visual symptoms are diagnosed (4). Because of diminished levels of argininosuccinate synthase and argininosuccinate lyase (14), the adult small intestine has a limited capacity to produce arginine, but continues to metabolize glutamine and proline for synthesis of citrulline, which is converted to arginine primarily by the kidney. 
The results of the present study demonstrate that OAT mRNA and enzymatic activity are present in intestinal epithelium of fetal pigs between d 30 and 110 of gestation (term, 114 $\pm 2 \mathrm{~d}$ ). It is noteworthy that de Jonge et al. (15) reported abundant OAT mRNA in small intestine of fetal rats on $\mathrm{d} 18$ of gestation, (term, $21 \mathrm{~d}$ ), a few days before birth. Although the functional significance of intestinal OAT during fetal development is not understood, its reversibility and position in the arginine biosynthetic pathway suggests that it may play a role in amino acid metabolism throughout gestation. More specifically, it may facilitate production of amino acids for fetal visceral organs and somatic growth throughout gestation.

The spatial expression of OAT mRNA in the fetal porcine small intestine changes during gestation. From d 30 to d 40, expression is detected in cells throughout the epithelium, whereas from d 45 to 110 of gestation, OAT mRNA expression is detected primarily in villus epithelium. The importance of this expression pattern is most relevant when taken into consideration with the expression patterns of other arginine metabolic enzymes (Fig. 1). For example, de Jonge et al. (15) reported different expression patterns along the villus-crypt axis for enzymes involved in citrulline biosynthesis and enzymes involved in conversion of citrulline to arginine in enterocytes of the developing mouse small intestine. This suggests compartmentalization of amino acid metabolic pathways within the mucosa of the small intestine, which is supported by results of this study. Enzymatic activities of proline oxidase, phosphate-dependent glutaminase, P-5-C synthase, carbamoyl phosphate synthase, ornithine carbamoyl transferase, argininosuccinate synthase, and argininosuccinate lyase have been detected in porcine fetal intestine throughout gestation (G. Wu, unpublished data). In conjunction with OAT expression patterns we report here, this may imply different roles for OAT in the different cell populations and during different stages of development; for example, the biosynthetic pathway may be driven toward the production of ornithine and polyamines before $\mathrm{d} 45$, when the intestine is proliferating rapidly, but shift toward the production of proline and extracellular matrix proteins concomitant with villus morphogenesis and enterocyte differentiation. Further studies of the mRNA expression patterns of these other enzymes in the arginine biosynthetic pathway within the epithelium of the fetal porcine small intestine will provide a better understanding of what role OAT may play in intestinal amino acid metabolism.

Because of the limited amount of intestinal tissue from $d$ 30-45 fetuses, whole intestines were used to determine intestinal OAT activity for these days of gestation. Potentially, inclusion of large intestinal tissue could inflate the experimentally determined value for OAT enzymatic activity by including OAT activity from colonic epithelium; however, this is not likely because previously reported data indicates that in pigs colonic OAT activity is low relative to the small intestine (5). This suggests that including large intestinal tissue in our enzyme assay may actually result in an underestimation of the OAT activity at the earlier stages of gestation. Additionally, at earlier stages of gestation, a proximal-distal gradient in the expression pattern of OAT suggests that the large intestine may have low OAT expression and thus low OAT activity.
During gestation the fetal small intestine is continually developing in preparation for extrauterine life, growing from a simple tube of endoderm into an organ resembling that found in the adult (7). These changes, which require cell proliferation and changes in extracellular matrix components (16), include the formation of villi and evolution of the stratified mucosa into a simple, differentiated epithelium (7). The presence of OAT mRNA and enzymatic activity in the immature, stratified epithelium of d 30 and 35 fetal small intestine and from d 40 to 110 suggests that these cells are capable of interconverting ornithine and P-5-C. The amino acid products in the arginine biosynthesis pathway (Fig. 1), in which OAT is a required enzyme, are needed for these synthetic processes throughout prenatal and postnatal life. Amino acids such as proline and ornithine may be synthesized and used locally within the small intestine for extracellular matrix and polyamine formation, respectively. In the pig, potential substrates for small intestinal metabolism, such as glutamine, which stimulates enterocyte proliferation (17) and promotes mucosal integrity (18), are available in swallowed amniotic fluid [rupture of stomodeum occurs before d 20 (19)] or through the fetal circulation from the placenta and allantois $(20,21)$. It is noteworthy that the majority of mucosal morphogenesis and cytodifferentiation of the fetal pig small intestine occurs between d 30 and 45 of gestation (7), a time when OAT activity in fetal pig intestine increases and when concentrations of ornithine and glutamine are particularly high in allantoic and amniotic fluids, respectively (21).

The relatively constant protein content of the intestine throughout gestation suggests that the observed changes in OAT activity are specific changes, and not a result of alterations in overall protein content of the developing intestine. The reason for the significant decrease in OAT enzymatic activity between d 45 and 60 of gestation is not clear. By d 60 of gestation, the major morphologic changes of the mucosa of the small intestine of fetal pigs appears to be complete (7). Therefore, the demand for locally produced and used amino acids in the small intestine may be temporarily reduced. Nonetheless, because of increased size of the small intestine with increasing fetal age, the total small intestinal OAT enzymatic activity of the fetus steadily increases with fetal age. It has been suggested that the small intestine of fetal humans and rabbits is an important source of enteral nutrition for somatic growth and development $(22,23)$. The fetal porcine small intestine may play a similar role, and this may be especially important at d 60 and thereafter, when the intestinal epithelium possesses absorptive and digestive capacities greater than those at earlier stages of gestation $(24,25)$ and is able to absorb amino acids from swallowed amniotic fluid. It should be noted that, in the pig, placental development is essentially complete by d 60 (26), and may also provide amino acids to the fetus during the latter stages of gestation. The relative importance of these two potential sources of amino acids to fetal somatic growth is unknown.

In most species, there exists little evidence to support a role for the fetal small intestine in overall fetal growth and devel- 
opment. However, most of those studies have focused on the provision of amnion-derived nutrients to the fetus rather than on the metabolic capacity of the fetal small intestine. The increase in OAT activity in the fetal small intestinal epithelium between $\mathrm{d} 60$ and 110 correlates with the major period of fetal development (26) and suggests that this intestinal enzyme plays a role during the latter stages of gestation. Similar to the role played by the neonatal and adult small intestine in arginine synthesis (5), the small intestine of fetal pigs may provide citrulline or arginine for the late stages of fetal growth and development. Substrates such as glutamine and proline (20) are present in both amniotic fluid and the fetal circulation and may be used for citrulline and arginine biosynthesis $(13,14)$. Synthesis of arginine by the fetal small intestine likely plays an important role in intrafetal provision of arginine during late gestation. Our recent studies with the pig suggest that the maternal supply of arginine is inadequate for arginine accretion in fetal pigs between d 110 and 114 of gestation (27).

In summary, results of the present study characterize changes in enzymatic activity and mRNA expression of OAT in the small intestine of fetal pigs. We found that OAT activity, expressed on a per milligram of protein basis, increases from $\mathrm{d}$ 30 to d 45 of gestation, a stage when major morphologic changes are taking place, decreases from d 45 to $\mathrm{d} 60$, and increases from d 60 to d 110 of gestation. The total small intestinal OAT enzymatic activity of the porcine fetus increases with increasing fetal age. OAT mRNA expression was detected within the mucosal epithelium from d 40 to 110 and was notably higher in villus epithelium than in cells of the crypts. The changing cellular distribution and compartmentalization of the OAT mRNA that accompanies intestinal differentiation suggest multiple roles for this enzyme throughout gestation. Additional studies are needed to better understand the role and importance of the fetal small intestine in amino acid metabolism, particularly its contribution to prenatal and perinatal arginine biosynthesis. Investigations to determine the function of intestinal OAT during gestation and potential regulators of intestinal OAT expression are ongoing in our laboratories.

Acknowledgments. The authors thank Dr. David Valle for provision of rat OAT cDNA. We also thank Dr. Robert Burghardt and the Texas A\&M College of Veterinary Medicine Image Analysis Laboratory for use of the image capturing system, and Dr. Fuller Bazer for his suggestions and critical review of this manuscript.

\section{REFERENCES}

1. Davis TA, Nguyen HV, Garcia-Bravo R, Fiorotto ML, Jackson EM, Lewis DS, Lee DR, Reeds PJ 1994 Amino acid composition of human milk is not unique. J Nutr 124:1126-1132

2. Wu G, Morris Jr SM 1998 Arginine metabolism: nitric oxide and beyond. Biochem J 336:1-17

3. Wu G, Meininger CJ, Knabe DA, Bazer FW, Rhoads JM 2000 Arginine nutrition in development, health and disease. Curr Opin Clin Nutr Metab Care 3:59-66

4. Wang T, Lawler AM, Steel G, Sipik I, Milam AH, Valle D 1995 Mice lacking ornithine-aminotransferase have paradoxical neonatal hypo-ornithinemia and retinal degeneration. Nat Genet 11:185-190

5. Flynn NE, Wu G 1996 An important role for endogenous synthesis of arginine in maintaining arginine homeostasis in neonatal pigs. Am J Physiol 271:R1149-R1155

6. Wu G, Knabe DA, Flynn NE 1994 Synthesis of citrulline from glutamine in pig enterocytes. Biochem J 299:115-121

7. Dekaney CM, Bazer FW, Jaeger LJ 1997 Mucosal morphogenesis and cytodifferentiation in fetal porcine small intestine. Anat Rec 249:517-523

8. Gupta A, Ing NH, Bazer FW, Bustamante LS, Jaeger LA 1998 Beta transforming growth factors $(\mathrm{TGF} \beta)$ at the porcine conceptus-maternal interface. Part I: expression of TGF $\beta 1$, TGF $\beta 2$, and TGF $\beta 3$ messenger ribonucleic acid. Biol Reprod 59:905-910

9. Wilcox J 1993 Fundamental principles of in situ hybridization. J Histochem Cytochem 41:1725-1733

10. Mueckler MM, Moran S, Pitot HC 1984 Transcriptional control of ornithine aminotransferase synthesis in rat kidney by estrogen and thyroid hormone. J Biol Chem 259:2302-2305

11. Mitchell GA, Looney JE, Brody LC, Steel G, Suchanek M, Engelhardt JF, Willard HF, Valle D 1988 Human ornithine- $\delta$-aminotransferase: cDNA cloning and analysis of the structural gene. J Biol Chem 263:14288-14295

12. Reeds PJ, Burrin DG, Stoll B, Jahoor F 2000 Intestinal glutamate metabolism. J Nutr 130:978S-982S

13. Wu G 1997 Synthesis of citrulline and arginine from proline in enterocytes of postnatal pigs. Am J Physiol 272:G1382-G1390

14. Wu G, Knabe DA 1995 Arginine synthesis in enterocytes of neonatal pigs. Am J Physiol 269:R621-R629

15. De Jonge WJ, Dingemase MA, de Boer PA, Lamer WH, Moorman AFM 1998 Arginine-metabolizing enzymes in the developing rat small intestine. Pediatr Res 43:442-451

16. Simon-Assmann P, Lefebvre O, Bellissent-Waydelich A, Olsen J, Orian-Rousseau V, De Arcangelis A 1998 The laminins: role in intestinal morphogenesis and differentiation. Ann N Y Acad Sci 859:46-64

17. Rhoads JM, Argenzio RA, Chen W, Rippe RA, Westwick JK, Cox AD, Berschneider HM, Brenner DA 1997 L-Glutamine stimulates intestinal cell proliferation and activates mitogen-activated protein kinases. Am J Physiol 272:G943-G953

18. Horvath K, Jami M, Hill ID, Papadimitriou JC, Magder LS, Chanasongcram S 1996 Isocaloric glutamine-free diet and the morphology and function of rat small intestine. J Parenter Enteral Nutr 20:128-134

19. Patten BM 1948 Embryology of the pig. Blakiston, New York, p 293

20. Wu G, Bazer FW, Tuo W 1995 Developmental changes in free amino acid concentrations in fetal fluids of pigs. J Nutr 125:2859-2868

21. Wu G, Bazer FW, Tuo W, Flynn SP 1996 Unusual abundance of arginine and ornithine in porcine allantoic fluid. Biol Reprod 54:1261-1265

22. Blakelock R, Upadhyay V, Kimble R, Pease P, Kolbe A, Harding J 1998 Is a normally functioning gastrointestinal tract necessary for normal growth in late gestation? Pediatr Surg Int 13:17-20

23. Jacobs DG, Wesson DE, Mago-Cao H, Muraji T, Konuma K, Mancer K, Kent G, Heim T 1989 Effect of esophageal ligation on the growth of fetal rabbits. J Pediatr Gastroenterol Nutr 8:245-251

24. Sangild PT, Sjöström H, Norén O, Fowden AL, Silver M 1995 The prenatal development and glucocorticoid control of brush-border hydrolases in the pig small intestine. Pediatr Res 37:207-212

25. Buddington RK, Malo C 1996 Intestinal brush-border membrane enzyme activities and transport functions during prenatal development of pigs. J Pediatr Gastroenterol Nutr 23:51-64

26. Knight JW, Bazer FW, Thatcher WW, Franke DE, Wallace HD 1977 Conceptus development in intact and unilaterally hysterectomized-ovarectomized gilts: interrelations among hormonal status, placental development, fetal fluids and fetal growth. J Anim Sci 44:620-637

27. Wu G, Ott TL, Knabe DA, Bazer FW 1999 Amino acid composition of the fetal pig. J Nutr 129:1031-1038 